\title{
Patients' perceptions toward and the driving factors of decision-making for opportunistic bilateral salpingectomy at the time of cesarean section
}

\section{Sezaryen sirasinda profilaktik bilateral salpenjektomiye hastaların bakıs açısı ve kararlarını etkileyen faktörler}

\author{
(1) Murat Yassal, (1) Çiğdem Pulatoğlu² \\ 1 Sancaktepe Şehit Prof. Dr. İthan Varank Training and Research Hospital, Clinic of Obstetrics and Gynecology, İstanbul, Turkey \\ 2İstinye University, Medical Park Gaziosmanpaşa Hospital, Clinic of Obstetrics and Gynecology, İstanbul, Turkey
}

\begin{abstract}
Objective: Enough data can be found in the literature regarding the protective effect of tubal ligation on gynecological cancers. In addition, a large body of evidence revealed that prophylactic bilateral salpingectomy had no significant negative effect on the ovarian function, quality of life, sexuality, surgery duration, and cost-effectivity. This study was aimed at exploring the underlying factors that motivate women for either opportunistic bilateral salpingectomy (OBS) or tubal ligation, particularly focusing on their preferences, knowledge, and beliefs toward female sterilization, satisfaction from counseling, and body image following the salpingectomy.

Materials and Methods: A total of 54 patients who had undergone surgical sterilization with either OBS or tubal ligation were included in this prospective cohort study. The acceptance rate of the OBS at the time of cesarean section among pregnant women seeking surgical sterilization was calculated. The underlying reasons for women's acceptance or refusal for salpingectomy were assessed by a non-validated data collection tool that had 14 open-ended questions focusing on the women's preferences, knowledge, beliefs toward female sterilization, satisfaction from counseling, and body image following the salpingectomy

Results: The acceptance rate of OBS at the time of cesarean section among pregnant women and electively among non-pregnant women were 93.5\% $(\mathrm{n}=43 / 46)$ and $75 \%(6 / 8)$, respectively. The main driving factors influencing the decision of preferring OBS over tubal ligation were the risk-reducing effect for ovarian cancer and superior pregnancy prevention.

Conclusion: The acceptance rate of OBS at the time of cesarean section was found to be very high, and it should therefore be offered at the time of cesarean section to women who desire permanent contraception.

Keywords: Opportunistic salpingectomy, permanent contraception, postpartum sterilization, prophylactic salpingectomy, risk-reducing salpingectomy

Öz

Amaç: Tubal ligasyonun jinekolojik kanserler üzerindeki koruyucu etkisi hakkında literatürde veriler vardır. Ayrıca, profilaktik bilateral salpinjektominin yumurtalık fonksiyonu, yaşam kalitesi, cinsellik, cerrahi süresi ve maliyet etkinliği üzerinde olumsuz bir etkisi olmadığı ortaya koyulmuştur. Bu çalışmada kadınların profilaktik bilateral salpinjektomi veya tubal ligasyon tercihlerini etkileyen faktörlerin araştırılması amaçlanmıştır.

Gereç ve Yöntemler: Bu prospektif kohort çalışmaya profilaktik bilateral salpinjektomi veya tubal ligasyon ile cerrahi sterilizasyon uygulanan toplam 54 hasta dahil edildi. Cerrahi sterilizasyon isteyen gebe kadınlarda sezaryen anında profilaktik bilateral salpinjektomiyi tercih edenlerin oranı belirlendi. Kadınların salpinjektomiyi seçmesinin veya reddetmesinin altında yatan nedenler, 14 açı uçlu soru içeren bir form ile değerlendirildi.

Bulgular: Gebelerin \%93,5’i (n=43/46) gebe olmayan kadınların ise \%75’i (6/8) sezaryen sırasında profilaktik bilateral salpinjektomiyi kabul etmişlerdir. Tubal ligasyon yerine profilaktik bilateral salpinjektomiyi tercih etmek için başlıca motivatörleri salfenjektominin over kanseri riskini azaltma ve kontrasepsiyondaki üstünlüğü olmuştur.
\end{abstract}

PRECIS: Obstetricians should be eager to offer opportunistic bilateral salpingectomy (OBS) at the time of cesarean section to women desiring permanent contraception following a detailed counseling of its potential benefits. The most common motivators of women for consenting to an OBS procedure were risk-reducing potential for ovarian cancer and superior pregnancy prevention.

Address for Correspondence/Yazışma Adresi: Çiğdem Pulatoğlu, MD,

İstinye University, Medical Park Gaziosmanpaşa Hospital, Clinic of Obstetrics and Gynecology, İstanbul, Turkey

Phone: +90 5365574462 E-mail: cigdempulatoglu@gmail.com ORCID ID: orcid.org/0000-0002-7595-3629

Received/Geliș Tarihi: 03.05.2020 Accepted/Kabul Tarihi: 10.05.2020

${ }^{\oplus}$ Copyright 2020 by Turkish Society of Obstetrics and Gynecology

Turkish Journal of Obstetrics and Gynecology published by Galenos Publishing House. 
Sonuç: Sezaryen sırasında profilaktik bilateral salpinjektomiyi kabul eden hastaların oranı yüksek bulunmuştur. Obstetrisyenler kalıcı kontrasepsiyon isteyen hastalara sezaryen sirasinda profilaktik bilateral salpinjektomiyi önermelidirler.

Anahtar Kelimeler: Profilaktik salpingektom, kalıcı kontrasepsiyon, postpartum sterilizasyon

\section{Introduction}

Tubal sterilization either with tubal occlusion or ligation and mid-isthmic partial salpingectomy is one of the most popular and effective methods of permanent contraception worldwide ${ }^{(1)}$. More than one-fifth women in the United States undergo a surgical female sterilization as a method of contraception ${ }^{(2)}$. Postpartum tubal ligation is performed after approximately $8-9 \%$ of all births. The cumulative 10-year probability of pregnancy is as low as $0.75 \%$.

There are now solid data about the protective effect of tubal ligation on gynecological cancers. A pooled systematic review and meta-analysis of all types of tubal procedures showed that tubal sterilization reduced the endometrial cancer risk approximately by $42 \%{ }^{(4)}$. Contrary to the endometrial cancer, epithelial ovarian cancer lacks an effective screening method and is the leading cause of mortality due to gynecological cancers in the developed countries, and the second highest globally ${ }^{(5)}$. It has been hypothesized previously that the fallopian tubes are very likely to be the origin of high-grade serous cancers ${ }^{(6)}$, and thus, prophylactic or opportunistic salpingectomy at the time for hysterectomy and other benign procedures may be beneficial. The incidence of ovarian cancer among women who had undergone prophylactic salpingectomy along with hysterectomy for benign condition was found to be reduced to $30-64 \%{ }^{(7)}$. In addition, a large body of evidence revealed that prophylactic bilateral salpingectomy had no significant negative effect on the ovarian function, quality of life, sexuality, surgery duration, and cost-effectivity ${ }^{(7)}$.

Prophylactic salpingectomy is a cost-effective and feasible strategy recommended for reducing the risk of ovarian cancer at the time of gynecologic surgery in women past childbearing age $^{(8)}$. A similar body of evidence for opportunistic approach at cesarean section is also growing. It has been calculated that opportunistic salpingectomy would lead to approximately 17 fewer ovarian cancer diagnoses, 13 fewer ovarian cancer deaths, and 25 fewer unwanted conceptions compared to tubal ligation for every 10,000 opportunistic salpingectomy at the time of cesarean section ${ }^{(9)}$.

However, salpingectomy refers to the surgical removal of a female reproductive organ. Some women may have apprehensions with respect to salpingectomy due to religious concerns, reduced self-image, or tubal re-anastomosis, and the decision-making process might be influenced by sociodemographic features and lack of knowledge ${ }^{(10-12)}$.

The investigators have experienced denials from women who were seeking tubal ligation as a sterilization procedure during cesarean section after a comprehensive counseling for prophylactic salpingectomy. It was aimed to explore the underlying factors that motivate women for either opport unistic bilateral solpingectomy (OBS) or tubal ligation, particularly focusing on their preferences, knowledge and beliefs toward female sterilization, satisfaction from counseling, and body image following the salpingectomy.

\section{Materials and Methods}

This descriptive cohort study was conducted at a secondary center between February and June 2019 and included women who agreed to surgical sterilization with either OBS or tubal ligation. The study was approved by the local administration board and registered with the National Clinical Trials Registry (NCT \#03830502). The study were approved by the University of Health Sciences Turkey, Şişli Hamidiye Etfal Training and Research Hospital Local Ethics Committee (approval number: 1182, date: 05/03/2019). Data were prospectively collected and retrospectively analyzed. The study included pregnant and non-pregnant women aged $>18$ years who either electively or at the time of cesarean section gave their consent for surgical sterilization. However, women with category-1 CS, clinical conditions that lead to planned cesarean hysterectomy such as placenta percreta, a history of ovarian cancer, previous chemotherapy or radiation, those who had previously undergone sterilization or withdrawn their consent prior to the surgery or whose surgical procedure could not be completed were excluded from the study. Once the patients' desire for sterilization was confirmed, surgical sterilization was discussed with the patients in the presence of indications. After the $32^{\text {th }}$ gestational week, pregnant women were initially approached with OBS during cesarean section as a primary surgical sterilization procedure. While a standard bilateral salpingectomy was performed in those who gave consent for salpingectomy, a tubal ligation with Pomeroy technique was performed in those who did not. For nonpregnant women, a laparoscopic tubal ligation was proposed rather than a hysteroscopic procedure due to technical and financial reasons. Further, pregnant women who had vaginal birth were proposed immediate contraception with intrauterine device or oral contraceptives; however, they were irrelevant to the objective of this study. While the primary outcome of the study was the acceptance rate of OBS at the time of cesarean section among pregnant women who seek surgical sterilization, the secondary outcomes were the patients' multifaceted perceptions toward sterilization and OBS and the driving factors behind the decision-making for OBS at the time of cesarean section. The secondary outcomes were measured using a non-validated data collection tool with 14 open-ended questions assessing the factors behind the decision of salpingectomy or tubal ligation (Table 1). The data collection tool did not have a scoring or a range and questioned the underlying reasons for women's acceptance or refusal to salpingectomy in detail, focusing on 
Table 1. Outline of the questionnaire

\section{Preference of the women toward the female sterilization}

Q1: Why did you prefer tubal operation among other methods?

Q4: Why did you not prefer oral contraceptives?

Q9: What is the leading reason of having tubal sterilization?

Q10: Whose wish was the tubal sterilization?

Q11: What is the leading reason of preferring the removal of tubes instead of tubal ligation?

Q12: If you prefer tubal ligation, what is the leading reason of not choosing the removal of tubes?

Knowledge of the women toward the female sterilization

Q2: Do you believe that you have enough knowledge about other contraception methods?

Q3: Is it possible to reopen your tubes following a tubal ligation and is the success rate high?

Q7: Do you think that you have enough information about what options do you have following the removal of tubes should you ever desire to having another child?

Q8: Do you have enough knowledge about the success rates of assisted reproductive techniques following the removal of tubes?

\section{Religious beliefs of the women about salpingectomy and tubal ligation}

Q5: Do you think it is a sin to have tubal ligation?

Q6: Do you think it is a sin to have the tubes removed?

\section{Satisfaction of the women with the counseling}

Q13: Are you satisfied with the counseling on the benefits of the removal of the tubes?

\section{Body image following the salpingectomy}

Q14: Do you think that you would feel incomplete following the removal of your tubes?

their preferences (Q1, 4, 9-12), knowledge (Q2, 3, 7, 8) and beliefs $(Q 5,6)$ toward female sterilization, satisfaction (Q13) from counseling, and body image following the salpingectomy (Q14). Finally, the open-ended answers were combined under similar answers. The income of the women were scaled between 1 and 3 (1: low-, 2: middle-, 3: high-income), and their occupations were scaled between 1 and 4 (1: unemployed, 2: worker, 3: government employee, 4: tradesmen/craftsmen). Informed consent was obtained.

\section{Statistical Analysis}

The data collected through the questionnaires were analyzed using the IBM SPSS Statistics (version 22.0; IBM Corporation, Armonk, NY). The demographic variables and specific scale measures were then presented as mean, standard deviation, standard error of mean, median, interquartile range (IQR), and frequency for the relevant items.

\section{Results}

A total of 58 women agreed to undergo a sterilization surgery and gave their consent for it. However, four women were later excluded from the study as three of them withdrew their consent for sterilization prior to the procedure and one of them had extensive adhesions due to which the procedure was abandoned in order not to increase the morbidity in the patient. Finally, a total of 54 surgical sterilization were performed (Figure 1).
The mean age of the women was $37.9 \pm 1.8$ years and ranged between 34 and 42 years. The mean body mass index was $28.9 \pm 3.8$ and ranged between 21 and 40. While the median parity was 3 (IQR: 2, minimum: 1, maximum: 6), the median income of the families was medium-income and the median occupation of the partner was governmental employee.

The acceptance rate of OBS at the time of cesarean section among pregnant women and electively among non-pregnant women were $93.5 \%(n=43 / 46)$ and $75 \%(6 / 8)$, respectively. The answers to the questions regarding the preferences (Q1, 4, 9-12), knowledge (Q2, 3, 7, 8) and beliefs (Q5, 6) toward female sterilization, satisfaction (Q13, 14) from counseling, and body image following the salpingectomy (Q15) were schematized (Figures 2-15).

\section{Discussion}

This study revealed that $91 \%$ of the participating women overwhelmingly preferred OBS over a standard tubal ligation. The women who preferred tubal ligation over OBS did so due a lack of knowledge about the procedure and further menstruation irregularities, possibility of re-opening of the tubes in the future, reduced body image, and influence of the partner. The main driving factor behind the decision preferring OBS over tubal ligation was the risk-reducing effect for ovarian cancer in 63\% of the patients. The second most common motivation was superior pregnancy prevention in 19\% of the women. 


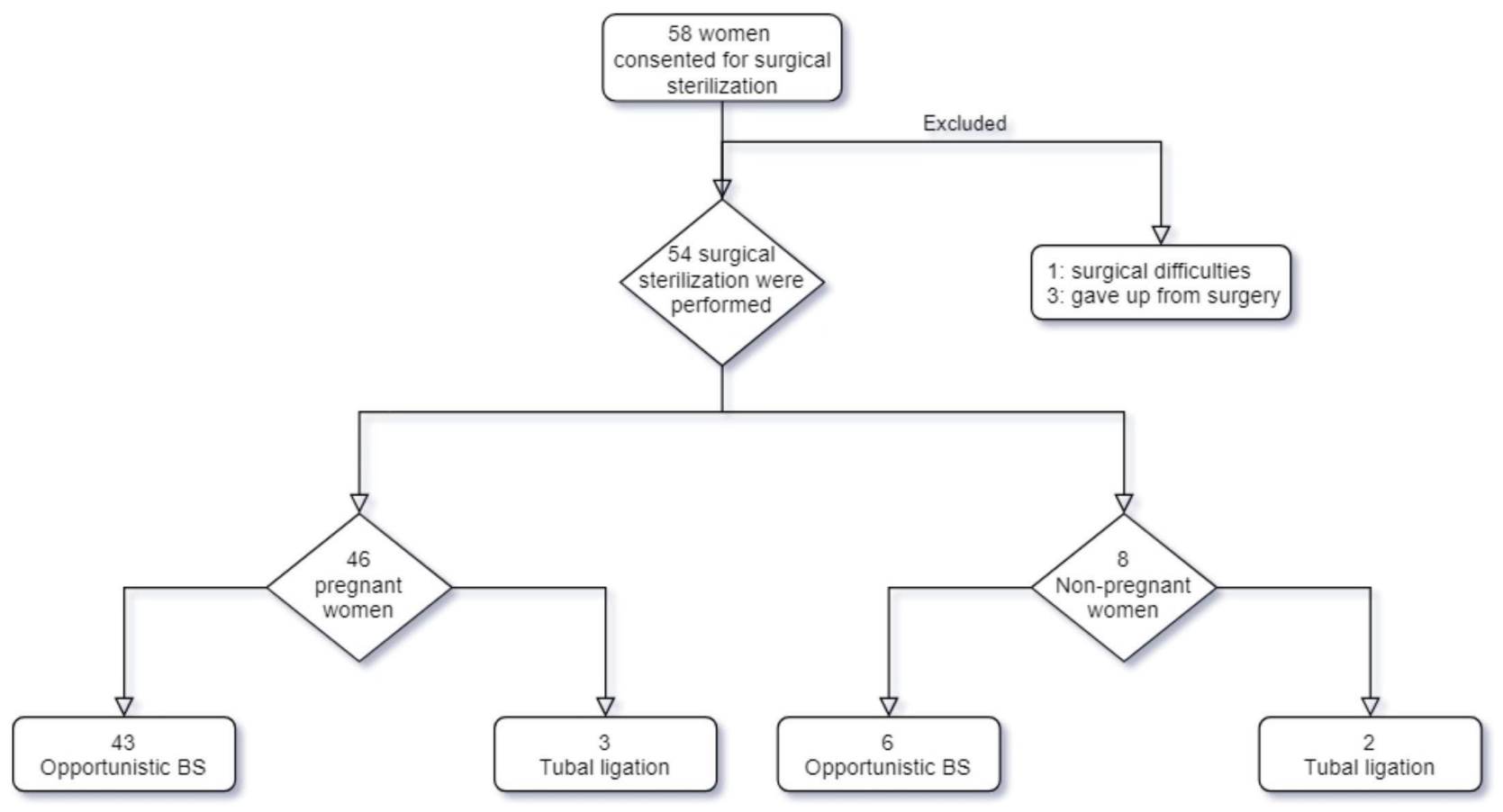

Figure 1. Flowchart of the women included in the study

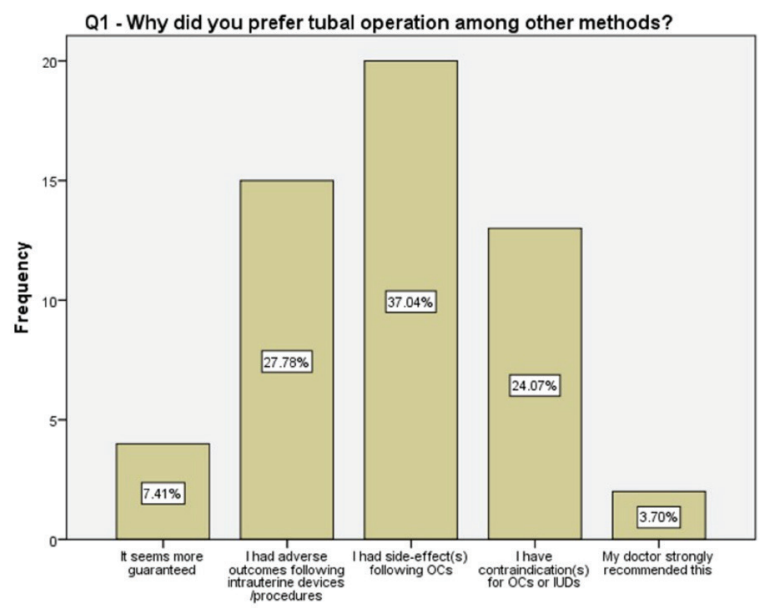

Figure 2. The reason for women's preference of tubal surgery

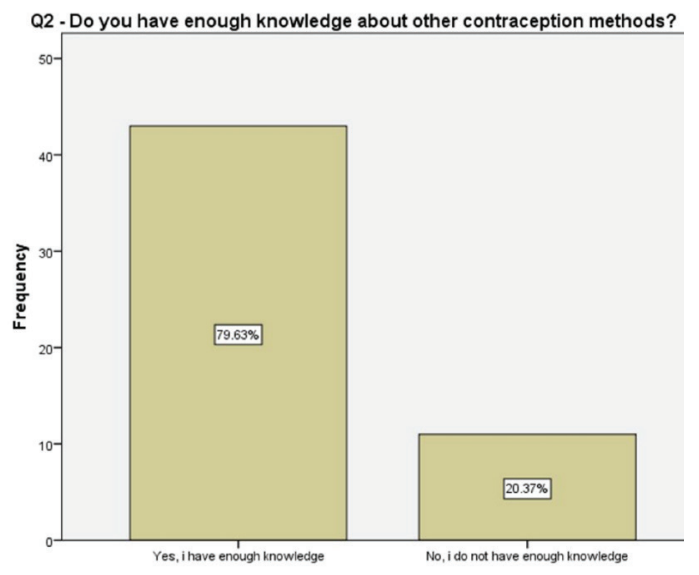

Figure 3. Women's knowledge of other contraception methods

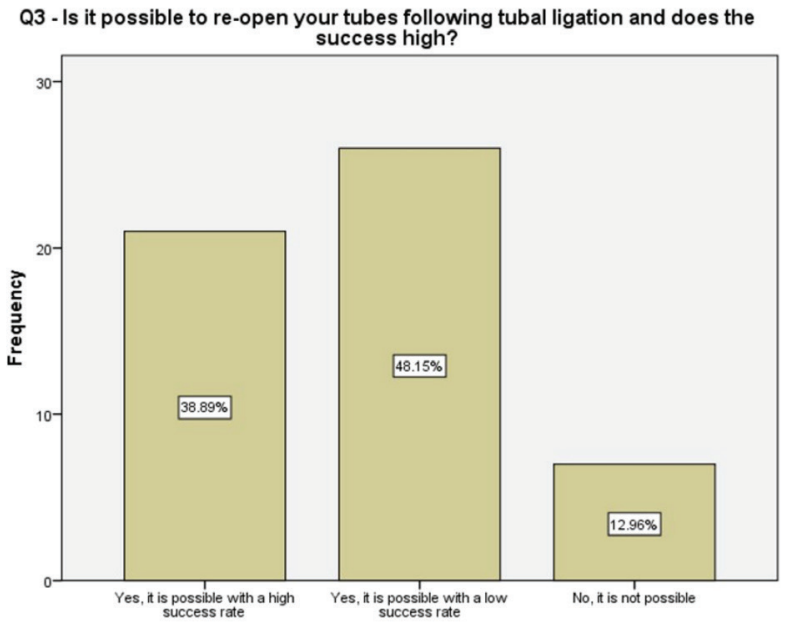

Figure 4. Women's knowledge toward the reversal of tubal ligation

A recent survey study of all women seeking permanent contraception revealed a high accepting OBS rate of $63 \%$ in pregnant and $85 \%$ in nonpregnant women ${ }^{(11)}$. Comparable to our results, the two main motivational factors for choosing salpingectomy were superior pregnancy prevention and risk reduction in ovarian cancer with $61 \%$ and $33 \%$, respectively ${ }^{(11)}$. OBS at the time of hysterectomy or interval sterilization has become a routine practice for reducing the risk of ovarian cancer. In 2015, an American College of Obstetricians and Gynecologists Committee Opinion recommended that obstetricians should discuss the possible risk-reducing benefits of bilateral salpingectomy with patients who wish to have permanent contraception ${ }^{(13)}$. However, the embracement of this strategy at the time of cesarean delivery for pregnant 


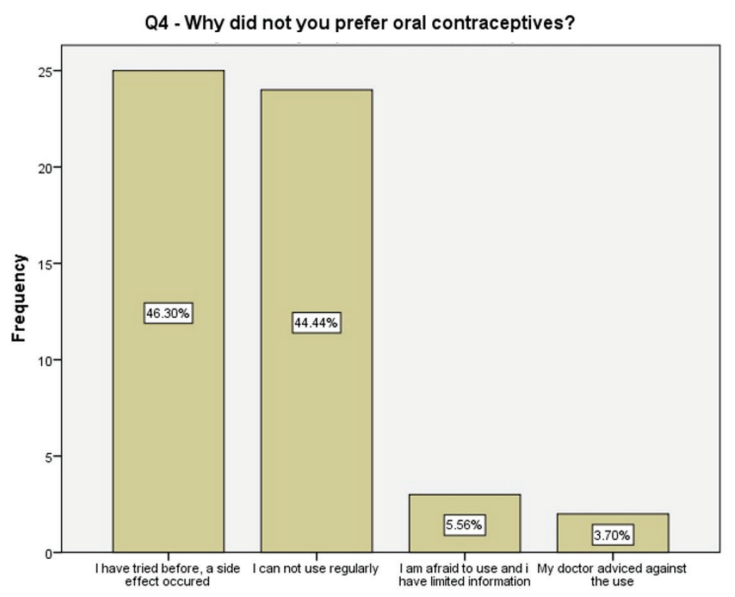

Figure 5. Underlying reasons for not choosing oral contraceptives

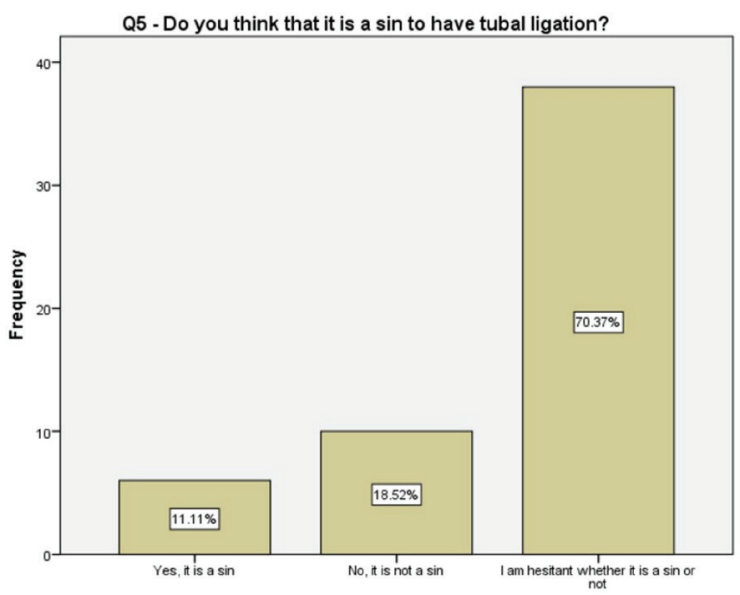

Figure 6. Women's religious beliefs toward the salpingectomy

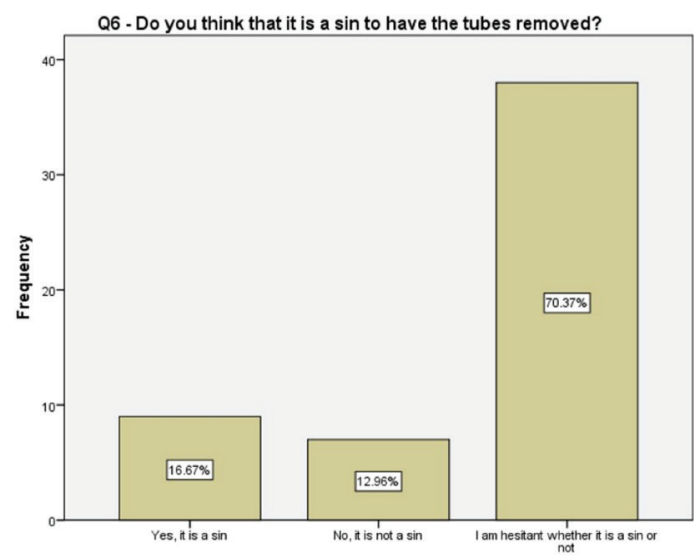

Figure 7. Women's religious beliefs toward the tubal ligation

women who desire permanent sterilization has not been widely adopted, probably due to a lack of available data including the surgical and psychological data in this setting ${ }^{(14)}$. By 2017, the overall proportion of salpingectomies in patients who underwent a permanent contraception procedure was reported to be as high as $61.5 \%$, in a nationwide data analysis ${ }^{(15)}$. In a large retrospective cohort study of seven years, almost half of the women preferred OBS as the mode of contraception at

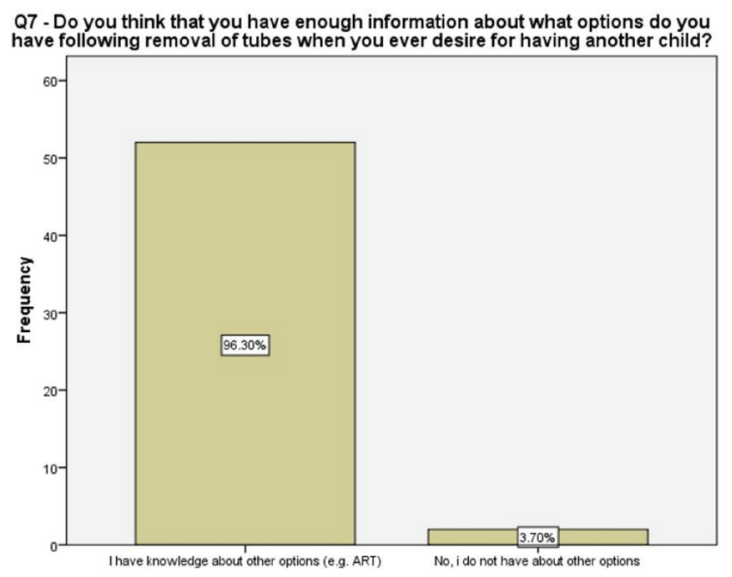

Figure 8. Women's knowledge of the future treatment options following the salpingectomy

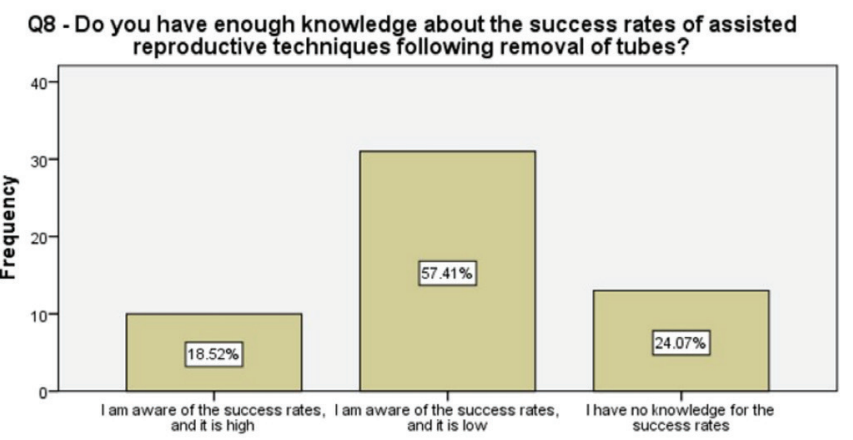

Figure 9. Women's knowledge of the success for future ART following the salpingectomy

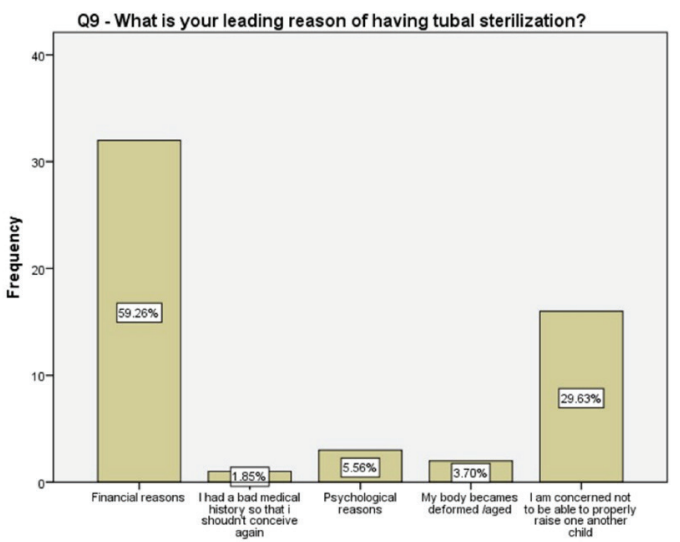

Figure 10. Women's main motivation for having tubal sterilization either elective or unscheduled cesarean section, which implies that OBS has a high acceptable rate for its higher contraceptive efficacy and risk-reduction benefit for ovarian cancer ${ }^{(16)}$.

About one-fifth of the women reported that they did not have enough information about other contraception methods prior to our detailed counseling, half of the women were not informed properly about the future recanalization of ligated fallopian tubes, 96\% of the women were familiar with the options that were available following a salpingectomy should 


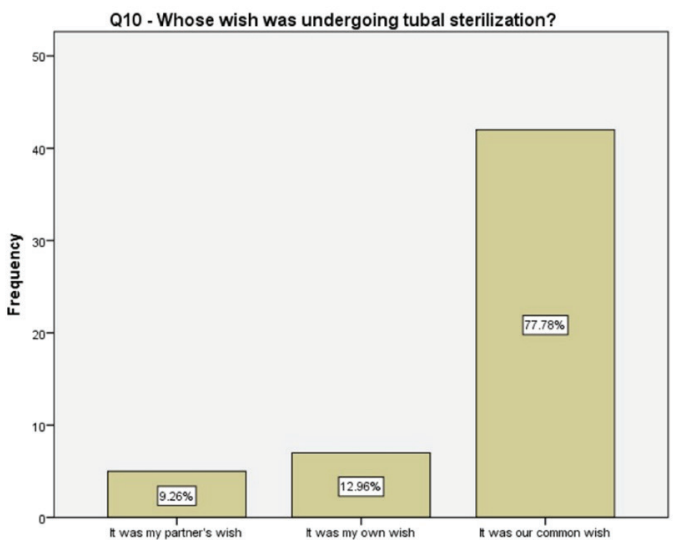

Figure 11. Decision-making on having tubal sterilization

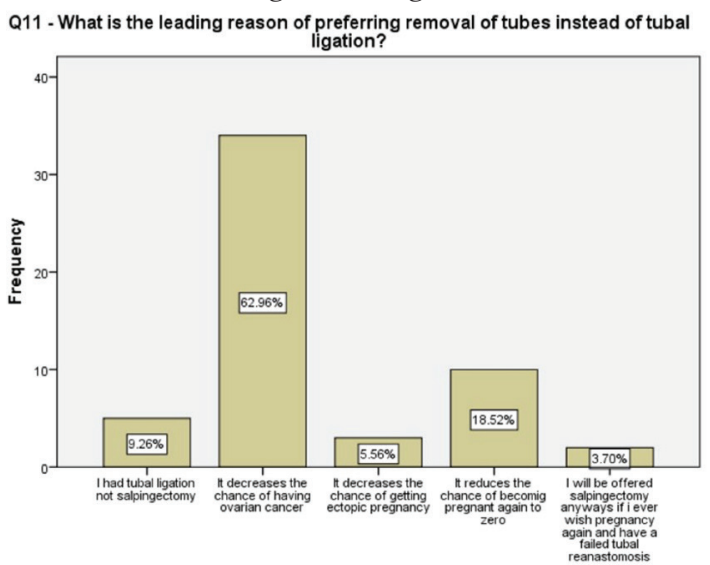

Figure 12. Women's main motivation for having salpingectomy instead of tubal ligation

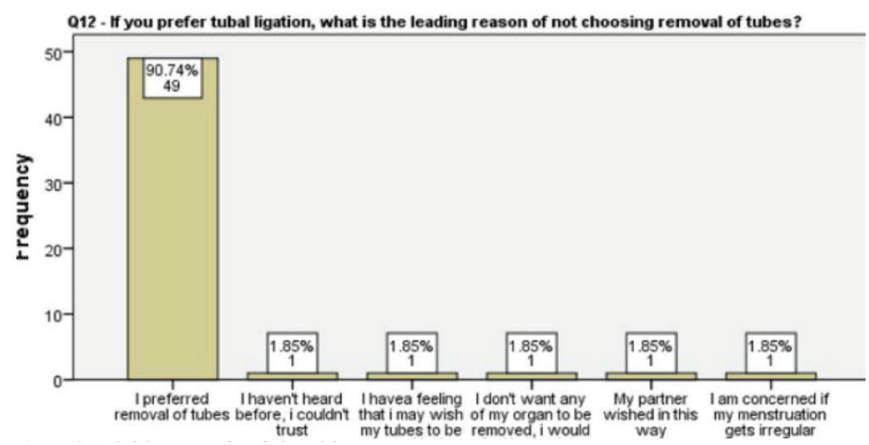

Figure 13. Underlying reasons for refusing salpingectomy

they desire fertility in future, and about $57 \%$ of them had accurate information about the success rates of future assisted reproductive techniques. These results enlightened the authors about the importance of the detailed counseling prior to suggesting the OBS option and, more importantly, encouraging the clinicians about non-inferiority of the procedure to comply with this risk-reducing strategy. A survey among physicians performing OBS reported that $46 \%$ of the surgeons had barriers such as suspicions about increased complications, decreased ovarian reserve, and increased counseling time while performing salpingectomy along with hysterectomy ${ }^{(17)}$. Therefore, a fully

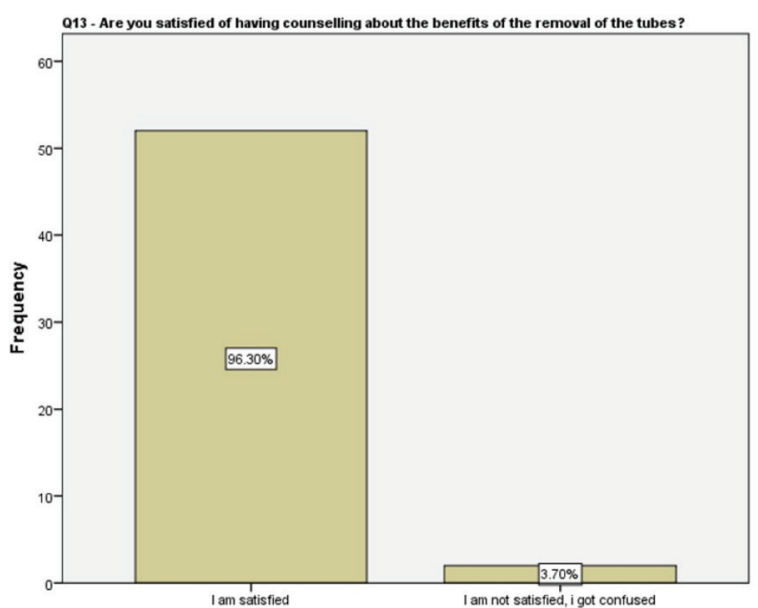

Figure 14. Women's satisfaction with the detailed counseling on salpingectomy

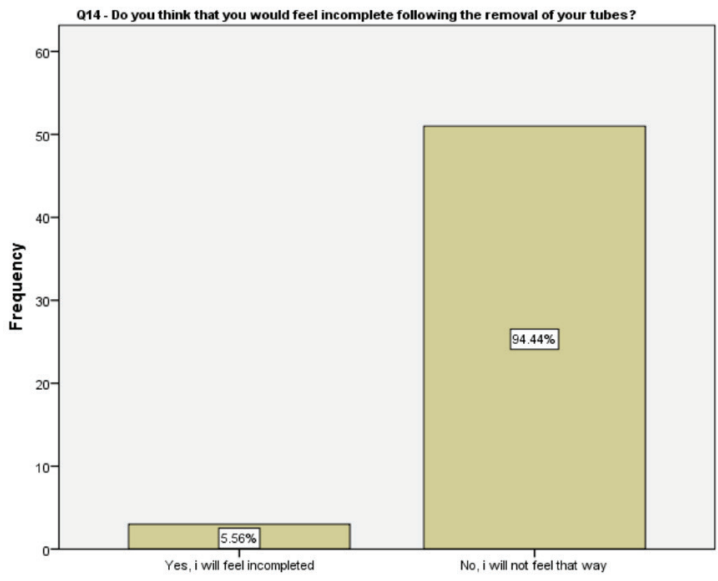

Figure 15. Women's body image upon salpingectomy

detailed counseling on the major advantages of OBS is crucial, following which, $96 \%$ of the women in our study reported being satisfied.

Of the women who preferred a tubal surgery in the current study, about $90 \%$ either had a contraindication for the use of other oral or intrauterine methods, or experienced side effects, or had difficulties on their regular use. Almost $60 \%$ of them sought permanent contraception due to financial difficulties and $30 \%$ expressed their concerns on raising more than one child. Although the women with two different answers surely had common thoughts, the latter may have underlying social and lifestyle difficulties that has to be investigated in future studies.

Interestingly, $70 \%$ of the women participating in this study were not sure if tubal ligation and removal of tubes are a sin or not. The authors could not find any related information in the literature while writing this article. However, despite that knowledge gap, majority of the women preferred salpingectomy. Although the authors have postulated that it might be related to their idea of body image, $95 \%$ of the women stated that they did not feel incomplete following the removal of fallopian tubes and 
losing their fertility. Determining the reasons and developing a strategy to overcome this issue and to increase the OBS rates are certainly the matters of future research.

A recent systematic review and meta-analysis of OBS at the time of cesarean section in women who underwent permanent sterilization revealed that although the bilateral salpingectomy slightly increased the operative time, it was comparable to tubal ligation in terms of complications, completion rate, and short-term ovarian reserve with a greater cost-effectiveness ${ }^{(18)}$. Another larger and more recent systematic review and metaanalysis determined similar results in which OBS was not associated with more adverse outcomes than tubal ligation ${ }^{(19)}$. Providing those favorable data to the women who seek permanent contraception might have affected the high consent rates for OBS in the current study.

However, while tubal sterilization is a highly effective method of contraception, its effectiveness varies by the surgical method, and the prevalence of regret has been reported to be between 0.9 and $26 \%$ with a cumulative probability of $12.7 \%^{(20)}$. Therefore, the future regret rates should be carefully assessed to better inform patients about the local circumstances. Authors postulated that the mean age of 38 years in the current study will probably reduce the regret rates, although they currently do not have the data.

Prophylactic and OBS is an increasing trend among obstetricians and has also proven to be an effective risk-reducing method for ovarian cancer. Future studies should focus on the underlying reasons behind last-minute refusals, the rates and features of unmet contraception needs, and the rates and outcome of patients who desire fertility again in the future following the OBS at the time of cesarean section.

\section{Study Limitations}

One of the limitations of the study is the small number of cases. The other limitation is the lack of data related to other factors like education, underlying reasons of last-minute refusals, the rates and features of unmet contraception needs which may also affect the decision of patients.

\section{Conclusion}

The acceptance rate of OBS at the time of cesarean section was found to be very high. The main driving factor behind the decision of preferring OBS over tubal ligation was its riskreducing effect for ovarian cancer and superior pregnancy prevention. Obstetricians are recommended to take every chance of offering OBS at the time of cesarean section to women who desire permanent contraception.

\section{Ethics}

Ethics Committee Approval: The study were approved by the University of Health Sciences Turkey, Şişli Hamidiye Etfal Training and Research Hospital Local Ethics Committee (approval number: 1182, date: 05/03/2019).

Informed Consent: It was obtained.
Peer-review: Externally peer-reviewed.

\section{Authorship Contributions}

Concept: M.Y., Ç.P., Design: M.Y., Ç.P., Data Collection or Processing: M.Y., Ç.P., Analysis or Interpretation: M.Y., Ç.P., Literature Search: M.Y., Ç.P., Writing: M.Y., Ç.P.

Conflict of Interest: No conflict of interest was declared by the authors.

Financial Disclosure: The authors declared that this study received no financial support.

\section{References}

1. Patil E, Jensen JT. Update on Permanent contraception options for women: Current Opinion in Obstetrics and Gynecology. Curr Opin Obstet Gynecol 2015;27:465-70.

2. Chan LM, Westhoff CL. Tubal sterilization trends in the United States. Fertil Steril 2010;94:1-6.

3. Peterson HB, Xia Z, Hughesa JM, Wilcox LS, Tylora LR, Trussell J. The risk of pregnancy after tubal sterilization: findings from the US Collaborative Review of Sterilization. Am J Obstet Gynecol 1996;174:1161-8; discussion 1168-70.

4. Loghmani L, Saedi N, Omani-Samani R, Safiri S, Sepidarkish M, Maroufizadeh S, et al. Tubal ligation and endometrial Cancer risk: a global systematic review and meta-analysis. BMC Cancer 2019;19:942.

5. Ferlay J, Soerjomataram I, Dikshit R, Eser S, Mathers C, Rebelo $\mathrm{M}$, et al. Cancer incidence and mortality worldwide: sources, methods and major patterns in GLOBOCAN 2012. Int J Cancer 2015;136:E359-86.

6. Shih I-M, Kurman RJ. Ovarian tumorigenesis: a proposed model based on morphological and molecular genetic analysis. Am J Pathol 2004;164:1511-8.

7. Anggraeni TD, Al Fattah AN, Surya R. Prophylactic salpingectomy and ovarian cancer: an evidence-based analysis. South Asian J Cancer 2018;7:42-5.

8. Subramaniam A, Blanchard CT, Erickson BK, Szychowski J, Leath CA, Biggio JR, et al. Feasibility of complete salpingectomy compared with standard postpartum tubal ligation at cesarean delivery: a randomized controlled trial. Obstet Gynecol 2018;132:20-7.

9. Subramaniam A, Einerson BD, Blanchard CT, Erickson BK, Szychowski J, Leath III CA, et al. The cost-effectiveness of opportunistic salpingectomy versus standard tubal ligation at the time of cesarean delivery for ovarian cancer risk reduction. Gynecol Oncol 2019;152:127-32.

10. Subramaniam A, Blanchard C, Erickson B, Szychowski J, Leath C, Biggio J, et al. Factors associated with completion and physician and patient attitudes towards salpingectomy at the time of cesarean delivery. Gynecol Oncol 2018;149:77.

11. Piazza A, Schwirian K, Scott F, Wilson MD, Zite NB, Creinin MD. Women's preferences for permanent contraception method and willingness to be randomized for a hypothetical trial. Contraception 2019;99:56-60.

12. Borrero S, Nikolajski C, Rodriguez KL, Creinin MD, Arnold RM, Ibrahim SA. "Everything I know I learned from my mother. or not": perspectives of African-American and white women on decisions about tubal sterilization. J Gen Intern Med 2009;24:312-9.

13. Committee on Gynecologic Practice. Committee opinion no. 620: Salpingectomy for ovarian cancer prevention. Obstet Gynecol 2015;125:279-81. 
14. Venkatesh KK, Clark LH, Stamilio DM. Cost-effectiveness of opportunistic salpingectomy vs tubal ligation at the time of cesarean delivery. Am J Obstet Gynecol 2019;220:106.e1-106.e10.

15. Polen-De C, Meganathan K, Lang P, Hohmann S, Jackson A, Whiteside JL. Nationwide salpingectomy rates for an indication of permanent contraception before and after published practice guidelines. Contraception 2019;100:111-5.

16. Ferrari F, Forte S, Prefumo F, Sartori E, Odicino F. Opportunistic salpingectomy during postpartum contraception procedures at elective and unscheduled cesarean delivery. Contraception 2019;99:373-6.

17. Garcia C, Martin M, Tucker L-Y, Lyon L, Armstrong MA, McBrideAllen S, et al. Experience with opportunistic salpingectomy in a large, community-based health system in the United States. Obstet Gynecol 2016;128:277-83.

18. Yang M, Du Y, Hu Y. Complete salpingectomy versus tubal ligation during cesarean section: a systematic review and meta-analysis. J Matern Fetal Neonatal Med 2019;1-9.

19. Roeckner JT, Sawangkum P, Sanchez-Ramos L, Duncan JR. Salpingectomy at the time of cesarean delivery: a systematic review and meta-analysis. Obstet Gynecol 2020;135:550-7.

20. Bartz D, Greenberg JA. Sterilization in the United States. Rev Obstet Gynecol 2008;1:23-32. 